Article

\title{
Dysprosium Acetylacetonato Single-Molecule Magnet Encapsulated in Carbon Nanotubes
}

\author{
Ryo Nakanishi ${ }^{1, *}$, Mudasir Ahmad Yatoo ${ }^{1}$, Keiichi Katoh ${ }^{1}$, Brian K. Breedlove ${ }^{1}$ \\ and Masahiro Yamashita ${ }^{1,2, *}$ \\ 1 Department of Chemistry, Graduate School of Science, Tohoku University, 6-3 Aza-Aoba, Aoba-ku, Sendai, \\ Miyagi 980-8578, Japan; muda.amu@gmail.com (M.A.Y.); kkatoh@m.tohoku.ac.jp (K.K.); \\ breedlove@m.tohoku.ac.jp (B.K.B.) \\ 2 WPI Research Center, Advanced Institute for Materials Research, Tohoku University, 2-1-1 Katahira, \\ Aoba-ku, Sendai 980-8577, Japan \\ * Correspondence: r.nakanishi@m.tohoku.ac.jp (R.N.); yamasita.m@gmail.com (M.Y.); \\ Tel.: +81-22-795-6544 (M.Y.)
}

Academic Editor: Wolfgang Linert

Received: 25 October 2016; Accepted: 20 December 2016; Published: 23 December 2016

\begin{abstract}
Dy single-molecule magnets (SMMs), which have several potential uses in a variety of applications, such as quantum computing, were encapsulated in multi-walled carbon nanotubes (MWCNTs) by using a capillary method. Encapsulation was confirmed by using transmission electron microscopy (TEM). In alternating current magnetic measurements, the magnetic susceptibilities of the Dy acetylacetonato complexes showed clear frequency dependence even inside the MWCNTs, meaning that this hybrid can be used as magnetic materials in devices.
\end{abstract}

Keywords: single-molecule magnet; carbon nanotube

\section{Introduction}

Single-molecule magnets (SMMs) [1-4], which are composed of isolated molecules, usually with large spin angular momenta $(S)$ in the ground state and strong uniaxial magnetic anisotropies $(D)$, exhibit an extensive range of functional properties, like magnetic bistability [1], quantum tunneling of magnetization [5-8], and quantum coherence [9]. Thus, they can be considered as not only molecular equivalents of classical bulk ferromagnets but also as next-generation quantum magnets. Therefore, SMMs are being developed for application in memory storage and in the processing of quantum information [10,11]. Moreover, novel applications of SMMs, including their use in molecular spintronics [12] and quantum computing [13], are being explored.

To use SMMs, we must be able to exploit the functionality of individual SMM molecules and combine them with other functional materials. There have been a few reports on combining SMMs with materials. For example, SMMs have been combined with carbon nanotubes (CNTs) [14] and graphene [15]. From these examples, when lanthanoid SMMs interact with nanocarbon materials, their electronic properties are affected. Another example involves the encapsulation of SMMs into nanoscopic one-dimensional pores, such as the internal nano-space of CNTs [16] and metal-organic frameworks [17], in which SMMs become aligned and their magnetic properties are controlled. SMM-nanomaterial hybrids may have new structures and unique physical properties. If SMMs are encapsulated in one-dimensional pores, the stacking structure can be controlled, and the SMM properties should be enhanced. Furthermore, when SMMs are encapsulated in CNTs, they are protected from the surrounding environment, and thus, the hybrids are easier to use in real applications. However, little has been reported on lanthanoid SMMs encapsulated inside CNTs. In this work, we encapsulated Dy acetylacetonato SMMs [18] in multi-walled CNTs (MWCNTs) by using a capillary 
method $[19,20]$. Encapsulation was verified by using transmission electron microscopy (TEM). It was shown that Dy complexes maintained their SMM-like properties in the MWCNTs.

\section{Results and Discussion}

\subsection{Synthesis}

MWCNTs with an internal diameter of $\sim 5 \mathrm{~nm}$ were purified by using centrifugation [21], and then the end-caps were opened by heating in air. The impurities in the internal nano-space were removed by heating in a vacuum. Next, Dy $(\mathrm{acac})_{3}\left(\mathrm{H}_{2} \mathrm{O}\right)_{2}$ was dissolved in 1,2-dichloroethane, and the solution was heated at $65{ }^{\circ} \mathrm{C}$ for $2 \mathrm{~h}$ to obtain a saturated solution. Cap-opened MWCNTs were added to the saturated solution and dispersed by using ultrasonication. Then the solution was left to stand for $3 \mathrm{~d}$ in order to encapsulate $\mathrm{Dy}(\mathrm{acac})_{3}\left(\mathrm{H}_{2} \mathrm{O}\right)_{2}$ into the MWCNTs via a capillary phenomenon $[19,20]$. After filtering and washing the surfaces with 1,2-dichloroethane, Dy $(\mathrm{acac})_{3}\left(\mathrm{H}_{2} \mathrm{O}\right)_{2}$ encapsulated in MWCNTs (Dy $(\mathrm{acac})_{3}\left(\mathrm{H}_{2} \mathrm{O}\right)_{2} @$ MWCNTs) were obtained.

\subsection{Transmission Electron Microscopy, Elemental Analysis and Thermogravimetry}

TEM was used to view the interior of the MWCNT hybrids; the structure images are illustrated in Figure 1a. In the TEM images, only Dy $(\mathrm{acac})_{3}\left(\mathrm{H}_{2} \mathrm{O}\right)_{2} @ M W C N T s$ as free-standing entities were observed, and there were no complexes on the external surfaces of the MWCNTs (Figure 1b). In enlarged images, a stark contrast between the Dy $(\mathrm{acac})_{3}\left(\mathrm{H}_{2} \mathrm{O}\right)_{2} @ \mathrm{MWCNT}$ (Figure 1c) and the empty MWCNTs was observed, as shown in Supplementary Materials Figure S1, showing that Dy $(\mathrm{acac})_{3}\left(\mathrm{H}_{2} \mathrm{O}\right)_{2}$ was encapsulated. In order to confirm the encapsulation and characterize the material present inside the MWCNTs, energy-dispersive X-ray (EDX) spectroscopy was used to detect the Dy ions (Figure 1d). The results clearly indicate that Dy $(\mathrm{acac})_{3}\left(\mathrm{H}_{2} \mathrm{O}\right)_{2}$ is encapsulated in the MWCNTs. Thermogravimetric analysis (TGA) was performed on pristine MWCNTs and Dy $(\text { acac })_{3}\left(\mathrm{H}_{2} \mathrm{O}\right)_{2} @ M W C N T$ (Figure 2). For the pristine MWCNTs, when $T>600{ }^{\circ} \mathrm{C}$, all of the carbon was lost as $\mathrm{CO}_{2}$. However, in the case of Dy $(\mathrm{acac})_{3}\left(\mathrm{H}_{2} \mathrm{O}\right)_{2} @ M W C N T, 22.3 \mathrm{wt} \%$ of a white compound remained even when $T>1000^{\circ} \mathrm{C}$. This material is thought to be $\mathrm{Dy}_{2} \mathrm{O}_{3}$. From the TGA data, the amount of Dy $(\mathrm{acac})_{3}\left(\mathrm{H}_{2} \mathrm{O}\right)_{2}$ was estimated to be $1.2 \mathrm{mmol}$ in $1 \mathrm{~g}$ of Dy(acac $)_{3}\left(\mathrm{H}_{2} \mathrm{O}\right)_{2} @ \mathrm{MWCNT}$.

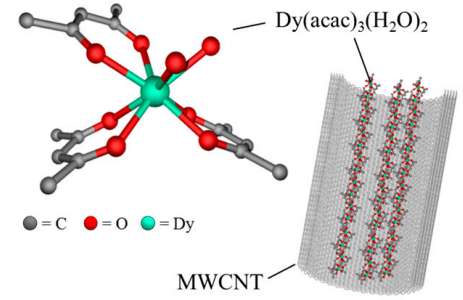

(a)

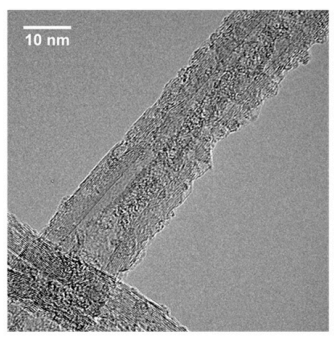

(c)

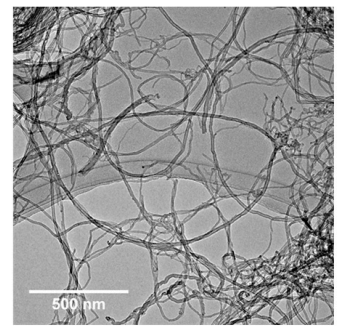

(b)

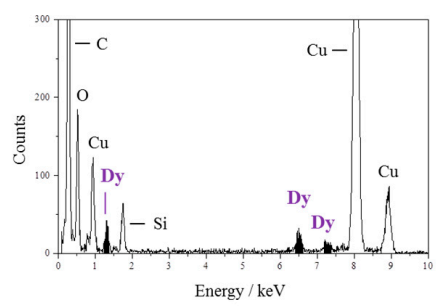

(d)

Figure 1. (a) Drawings of Dy (acac $)_{3}\left(\mathrm{H}_{2} \mathrm{O}\right)_{2}$ complex and the complexes encapsulated in multi-walled carbon nanotubes (MWCNT); (b) Low magnification and (c) high magnification transmission electron microscopy (TEM) images of Dy $(\mathrm{acac})_{3}\left(\mathrm{H}_{2} \mathrm{O}\right)_{2} @$ MWCNTs; (d) energy dispersive X-ray spectroscopy (EDX) spectrum acquired for the sample in (c). 


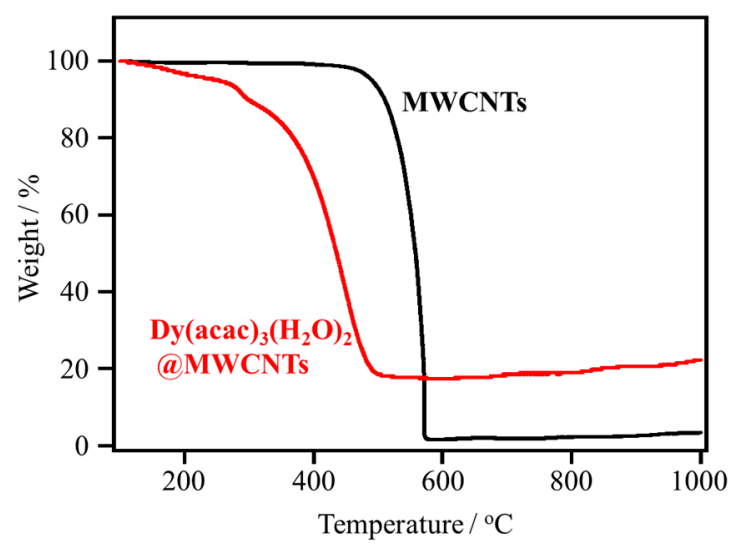

Figure 2. Thermogravimetric analyses of empty MWCNTs (black) and Dy $(\text { acac })_{3}\left(\mathrm{H}_{2} \mathrm{O}\right)_{2} @ M W C N T s$ (red).

\subsection{Magnetic Properties}

To determine the effects of encapsulation of the SMMs in MWCNTs on the magnetic properties, both static and dynamic magnetic measurements on Dy $(\mathrm{acac})_{3}\left(\mathrm{H}_{2} \mathrm{O}\right)_{2} @ \mathrm{MWCNTs}$ were performed, and the results were compared with those for free Dy complexes. Direct current (DC) measurements were used to obtain molar magnetic susceptibilities $\left(\chi_{\mathrm{m}}\right)$, which depended on $T$ and the magnetic field $(H) \cdot \chi_{\mathrm{m}} T-T$ plots for Dy $(\mathrm{acac})_{3}\left(\mathrm{H}_{2} \mathrm{O}\right)_{2} @ M W C N T s$ and pure Dy $(\mathrm{acac})_{3}\left(\mathrm{H}_{2} \mathrm{O}\right)_{2}$ are shown in Figure 3a. After correcting the diamagnetism of the MWCNTs (see Supplementary Materials Figure $\mathrm{S} 2$ ), we determined the $\chi_{\mathrm{m}}$ values for $\mathrm{Dy}(\mathrm{acac})_{3}\left(\mathrm{H}_{2} \mathrm{O}\right)_{2} @ \mathrm{MWCNTs}$ by using the ratio obtained from TGA, and the resulting $\chi_{\mathrm{m}} T$ value at $300 \mathrm{~K}$ agrees with that for an isolated Dy(III) ion $\left(14.2 \mathrm{~cm}^{3} \cdot \mathrm{K} \cdot \mathrm{mol}^{-1}\right)$, which suggests that the estimated amount of $\operatorname{Dy}(\mathrm{acac})_{3}\left(\mathrm{H}_{2} \mathrm{O}\right)_{2}$ is reliable. $\chi_{\mathrm{m}} T$ values for Dy(acac $)_{3}\left(\mathrm{H}_{2} \mathrm{O}\right)_{2} @ M W C N T s$ decreased with a decrease in $T$, whereas those for pure $\operatorname{Dy}(\text { acac })_{3}\left(\mathrm{H}_{2} \mathrm{O}\right)_{2}$ did not. This difference was ascribed to depopulation of high energy $m_{\mathrm{J}}$ states due to configurational and orientational changes in the ligands upon encapsulation [22,23].

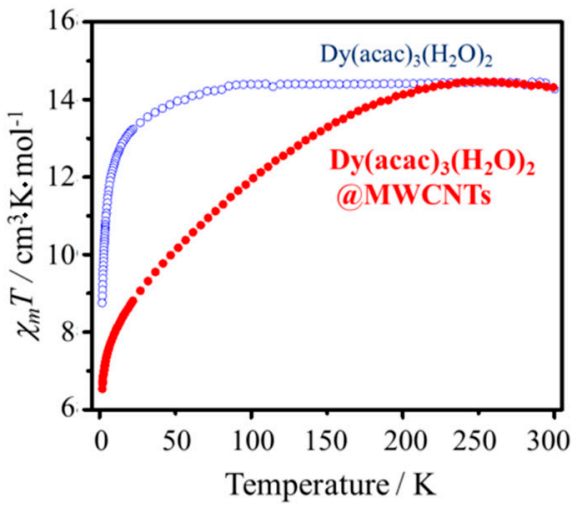

(a)

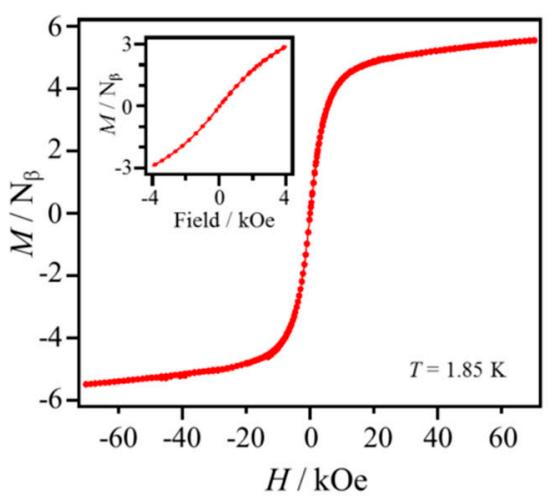

(b)

Figure 3. (a) $\chi_{\mathrm{m}} \mathrm{T}$ vs. $\mathrm{T}$ plots for $\mathrm{Dy}(\mathrm{acac})_{3}\left(\mathrm{H}_{2} \mathrm{O}\right)_{2} @ \mathrm{MWCNTs}$ (red filled circles) and pure Dy(acac) $)_{3}\left(\mathrm{H}_{2} \mathrm{O}\right)_{2}$ (blue open circles); (b) $M$ vs. $H$ plots for Dy $(\mathrm{acac})_{3}\left(\mathrm{H}_{2} \mathrm{O}\right)_{2} @ M W C N T s$ at $1.85 \mathrm{~K}$. The inset shows magnified curve in the range of $-4-4 \mathrm{kOe}$.

In magnetization $(M)$ vs. $H$ plots, shown in Figure $3 \mathrm{~b}$, magnetic hysteresis was not observed. In the case of Dy $(\mathrm{acac})_{3}\left(\mathrm{H}_{2} \mathrm{O}\right)_{2}$ diluted with 20 equivalents of $\mathrm{Y}(\mathrm{acac})_{3}\left(\mathrm{H}_{2} \mathrm{O}\right)_{2}$, slight hysteresis has been observed at $2 \mathrm{~K}$ because the distance between each Dy $(\mathrm{acac})_{3}\left(\mathrm{H}_{2} \mathrm{O}\right)_{2}$ is large and quantum tunneling of the magnetization (QTM) is suppressed [18]. Therefore, QTM is not suppressed for the Dy $(\mathrm{acac})_{3}\left(\mathrm{H}_{2} \mathrm{O}\right)_{2} @ M W C N T s$. In addition, it is possible that the coordination environment of 
Dy $(\mathrm{acac})_{3}\left(\mathrm{H}_{2} \mathrm{O}\right)_{2}$ changed upon encapsulation in the MWCNTs, which promotes the QTM process and shortens the relaxation time. Similar behavior for $\mathrm{Mn}_{12}$-acetate SMMs encapsulated in MWCNTs has been reported [16]. In other words, no hysteresis was observed for the Dy hybrids. Thus, by controlling the coordination environment via encapsulation in CNTs, the relaxation time of the SMMs can be tuned.

Next, the dynamic magnetic properties were studied, and the results are shown in Figure 4. For Dy $(\mathrm{acac})_{3}\left(\mathrm{H}_{2} \mathrm{O}\right)_{2} @ M W C N T s$, an out-of-phase $\left(\chi^{\prime \prime}\right)$ signal, which is indicative of slow relaxation of $M$, was observed. Furthermore, both the in-phase $\left(\chi^{\prime}\right)$ and $\chi^{\prime \prime}$ signals were frequency dependent. This dependence is due to the Dy $(\mathrm{acac})_{3}\left(\mathrm{H}_{2} \mathrm{O}\right)_{2}$ complexes because the susceptibilities of the MWCNTs themselves are not frequency dependent (Supplementary Materials Figure S3). These results indicate that the observed slow relaxation is due to SMM behavior, that is, there is an energy barrier for relaxation of the magnetic moment even inside the MWCNTs. However, there was no peak top for the $\mathrm{Dy}(\mathrm{acac})_{3}\left(\mathrm{H}_{2} \mathrm{O}\right)_{2} @ M W C N T s$ in the frequency range of 1-1000 Hz, whereas a clear peak top was observed for the pure complex (Supplementary Materials Figure S4). As seen in Figure 4b, peak top values of $\chi^{\prime \prime}$ shifted towards higher frequencies. This indicates that the relaxation times for the hybrids are faster than those for the pure complex. In the $\chi^{\prime \prime}$ versus $T$ plots shown in Figure 5a, a peak top was still observed in the $T$ region below $2 \mathrm{~K}$, indicating that the magnetic moment was not frozen and that a different relaxation process, like QTM process, was dominant in the low- $T$ region. We estimated the pre-exponential factor $\tau_{0}$ and the activation energy $\Delta E$ from $\chi^{\prime \prime} / \chi^{\prime}$ versus $T^{-1}(6-10 \mathrm{~K})$ plots, shown in Figure $5 b$, in the $v$ range of $240-1103 \mathrm{~Hz}$ by using the Kramers-Kronig equation [23-27]:

$$
\begin{gathered}
\chi^{\prime \prime} / \chi^{\prime}=\omega \tau \\
\chi^{\prime \prime} / \chi^{\prime}=\omega \tau_{0}+\exp \left(\Delta E / k_{B} T\right) \\
\ln \left(\chi^{\prime \prime} / \chi^{\prime}\right)=\ln \left(\omega \tau_{0}\right)+\Delta E / k_{B} T
\end{gathered}
$$

where $\omega(=2 \pi v)$ is the angular frequency. By fitting the data, the $\tau_{0}$ and $\Delta E$ for $\mathrm{Dy}(\mathrm{acac})_{3}\left(\mathrm{H}_{2} \mathrm{O}\right)_{2} @ M W C N T s$ were estimated to be in the range of $10^{-6}-10^{-7} \mathrm{~s}$ and $4-5 \mathrm{~cm}^{-1}$, respectively (Supplementary Materials Table S1). For pure Dy $(\mathrm{acac})_{3}\left(\mathrm{H}_{2} \mathrm{O}\right)_{2}, \tau_{0}$ and $\Delta E$ were determined to be $8.0 \times 10^{-7} \mathrm{~s}$ and $45.9 \mathrm{~cm}^{-1}$, respectively [18]. We think that $\Delta E$ for the hybrids is lower because of a conformational change in Dy $(\mathrm{acac})_{3}\left(\mathrm{H}_{2} \mathrm{O}\right)_{2}$ inside the MWCNTs. The values are consistent with the decrease in the $\chi_{\mathrm{m}} T$ value and magnetic hysteresis behavior.

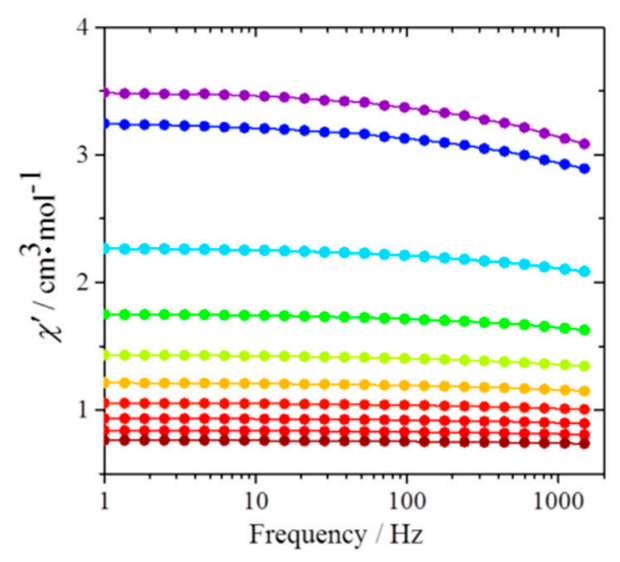

(a)

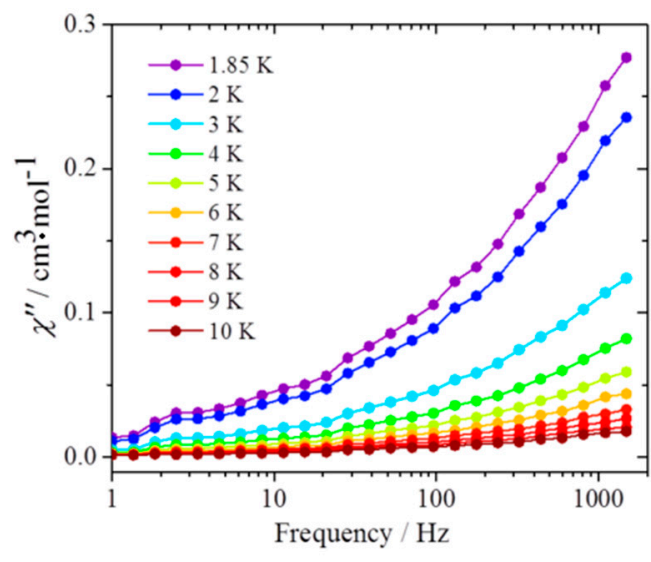

(b)

Figure 4. Frequency dependence of the (a) in-phase $\left(\chi^{\prime}\right)$ and (b) out-of-phase $\left(\chi^{\prime \prime}\right)$ AC magnetic susceptibilities of Dy $(\mathrm{acac})_{3}\left(\mathrm{H}_{2} \mathrm{O}\right)_{2} @$ MWCNTs. The measurements were performed in an $\mathrm{H}_{\mathrm{DC}}$ of 0 Oe and $H_{\mathrm{AC}}$ of $3 \mathrm{Oe}$ in the $T$ range of $1.85-10 \mathrm{~K}$. The solid lines are guides for eyes. 


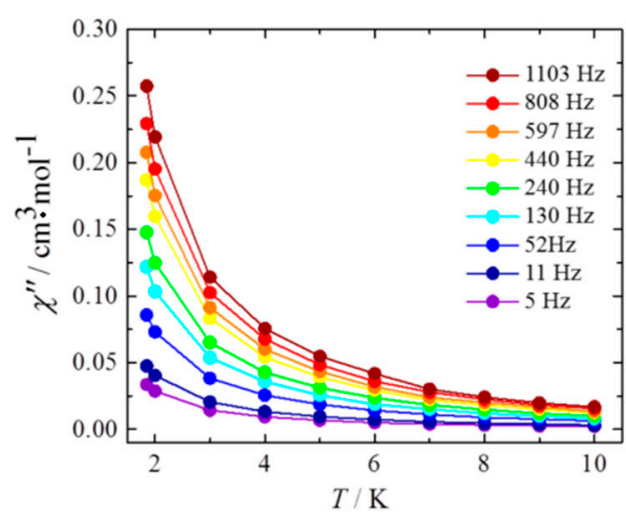

(a)

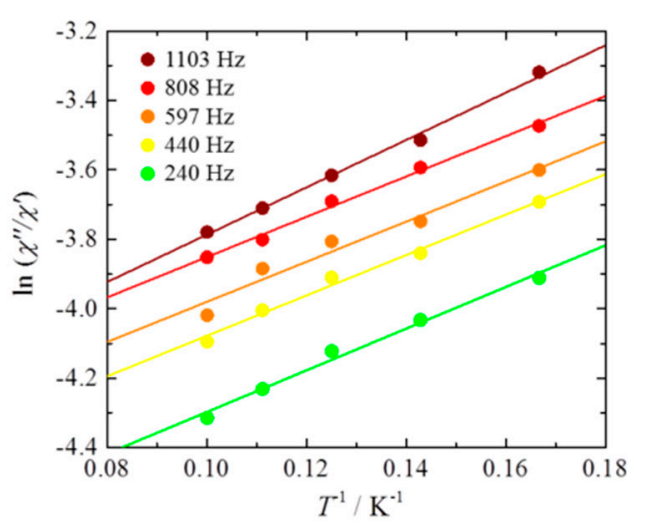

(b)

Figure 5. (a) $\chi^{\prime \prime}$ vs. T plots for $\mathrm{Dy}(\mathrm{acac})_{3}\left(\mathrm{H}_{2} \mathrm{O}\right)_{2} @ M W C N T s$. The solid lines are guides for eyes; (b) $\chi^{\prime \prime} / \chi^{\prime}$ versus $T^{-1}(6-10 \mathrm{~K})$ plot in the $v$ range of $240-1103 \mathrm{~Hz}$. The solid lines were fitted as described in Supplementary Materials Table S1.

\section{Materials and Methods}

\subsection{General}

Distilled water was obtained from a EYELA STILL ACE SA-2100E deionizer (Tokyo Rikakikai Co., Ltd., Tokyo, Japan). Dy (acac $)_{3}\left(\mathrm{H}_{2} \mathrm{O}\right)_{2}$ (STREM Chemicals, Inc., Newburyport, MA, USA), 1,2-dichloroethane and methanol (Wako Pure Chemical Industries, Ltd., Osaka, Japan) were used as received. MWCNTs synthesized by using the CoMoCAT ${ }^{\mathrm{TM}}$ catalytic chemical vapor deposition method with outer diameters of $10 \pm 0.1 \mathrm{~nm}$, inner diameters of $4.5 \pm 0.5 \mathrm{~nm}$, and lengths of 3-6 $\mu \mathrm{m}$ (Sigma-Aldrich Co. LLC., St. Louis, MO, USA) were purchased and used after removing the magnetic impurities by using a centrifugation method [21]. The MWCNTs (30 mg) were dispersed with $60 \mathrm{~mL}$ of $1 \mathrm{wt} \%$ sodium cholate in water by using ultrasonication with a tip-type sonicator (UP200S, Hielscher Ultrasonics $\mathrm{GmbH}$, Teltow, Germany). The obtained black suspension was centrifuged at 18,500 rpm for $\sim 1 \mathrm{~h}$ using a tabletop centrifuge (AS185, AS ONE Co., Osaka, Japan), and the upper $80 \%$ of the supernatant was collected. The well-dispersed MWCNTs were aggregated by adding methanol and filtered over a Kiriyama filter (Kiriyama glass Co., Tokyo, Japan) having a pore size of $1 \mu \mathrm{m}$. The aggregates were then washed with excess methanol and dried at $200{ }^{\circ} \mathrm{C}$ in a vacuum overnight, affording $15 \mathrm{mg}$ of purified MWCNT buckypaper.

\subsection{Synthesis}

Purified MWCNTs were decapped by heating at $550{ }^{\circ} \mathrm{C}$ for $5 \mathrm{~min}$ in air and degassed by heating in a vacuum just before using. To a saturated solution of Dy $(\mathrm{acac})_{3}\left(\mathrm{H}_{2} \mathrm{O}\right)_{2}$ in $10 \mathrm{~mL}$ of 1,2-dichloroethane, which was heated at $65^{\circ} \mathrm{C}$ for about $2 \mathrm{~h}$ to ensure that Dy $(\mathrm{acac})_{3}\left(\mathrm{H}_{2} \mathrm{O}\right)_{2}$ dissolved as much as possible, $10 \mathrm{mg}$ of decapped MWCNTs were added. After $5 \mathrm{~min}$ of ultrasonication using a bath-type sonicator and letting stand for $3 \mathrm{~d}$, MWCNTs were collected by filtration and washed with 1,2-dichloroethane to completely remove the Dy $(\mathrm{acac})_{3}\left(\mathrm{H}_{2} \mathrm{O}\right)_{2}$ from the surfaces of the MWCNTs.

\subsection{TEM Observation}

High-resolution transmission electron microscopy (TEM) and energy dispersive $\mathrm{X}$-ray spectroscopy (EDX) were carried out using a JEM2100F (acceleration voltage; $200 \mathrm{kV}$, JEOL Ltd., Tokyo, Japan) with dry SD30GV detector (JEOL Ltd., Tokyo, Japan). The sample was dispersed in methanol and deposited on a carbon-coated $\mathrm{Cu}$ grid, which was dried by heating overnight at $100^{\circ} \mathrm{C}$ in a $10^{-4}$ Pa vacuum before TEM was performed. 


\subsection{Thermogravimetric Analysis}

Thermogravimetric analysis (TGA) was performed on a SHIMADZU DTG-60 (Shimadzu Corporation, Kyoto, Japan) using aluminum oxide powder as a standard material. Several milligrams of the sample were put in an aluminum cell, and the cell was heated to $1000{ }^{\circ} \mathrm{C}$ with a heating rate of $2{ }^{\circ} \mathrm{C} / \mathrm{min}$.

\subsection{Magnetic Susceptibility Measurement}

Magnetic susceptibility measurements were performed on a SQUID magnetometer (model MPMS-XL SQUID magnetometer, Quantum Design, Inc., San Diego, CA, USA). Samples were put into gelatin capsules, and eicosane was added to fix the samples during the measurement. DC measurements for Dy (acac $)_{3}\left(\mathrm{H}_{2} \mathrm{O}\right)_{2}$ were performed in an $\mathrm{H}_{\mathrm{DC}}$ of $500 \mathrm{Oe}$, and those for the purified MWCNTs and Dy (acac $)_{3}\left(\mathrm{H}_{2} \mathrm{O}\right)_{2} @ M W C N T s$ were recorded in $H_{\text {DC }}$ of 1000 Oe. $T$ was changed from $300 \mathrm{~K}$ to $1.85 \mathrm{~K}$ with a sweep rate of $1 \mathrm{~K} / \mathrm{min}$. Field dependent DC measurements were performed at $1.85 \mathrm{~K}$ while changing the magnetic field as follows: $0 \mathrm{Oe} \rightarrow 70 \mathrm{kOe} \rightarrow-70 \mathrm{kOe} \rightarrow 70 \mathrm{kOe}$. $\mathrm{AC}$ measurements were recorded in an $\mathrm{H}_{\mathrm{AC}}$ of $3 \mathrm{Oe}$ in the frequency range of 1-1500 $\mathrm{Hz}$ and $\mathrm{T}$ range of 1.85-10 K. Diamagnetic contributions from the eicosane and Dy $(\mathrm{acac})_{3}\left(\mathrm{H}_{2} \mathrm{O}\right)_{2}$ were corrected by using Pascal's constants, and then the magnetic susceptibility for the purified MWCNTs was subtracted from that for Dy (acac $)_{3}\left(\mathrm{H}_{2} \mathrm{O}\right)_{2} @$ MWCNTs. Magnetic moments $\chi_{\mathrm{CNT}}, \chi_{\mathrm{CNT}}{ }^{\prime}$ and $\chi_{\mathrm{CNT}}{ }^{\prime \prime}$ (Supplementary Materials Figures S2 and S3) were obtained by normalizing the obtained magnetic moments with the mass of CNT after applying the diamagnetic corrections.

\section{Conclusions}

In this work, we encapsulated Dy(acac $)_{3}\left(\mathrm{H}_{2} \mathrm{O}\right)_{2}$ SMMs in the internal nanospace of MWCNTs by using a capillary method. Encapsulation was confirmed by using TEM. From AC magnetic susceptibility measurements, both the in-phase and out-of-phase signals were clearly frequency dependent, indicating that Dy (acac $)_{3}\left(\mathrm{H}_{2} \mathrm{O}\right)_{2}$ complexes still exhibited SMM-like properties. To the best of our knowledge, this is the first example of a lanthanoid SMM encapsulated in CNTs. Although the encapsulation of Dy $(\mathrm{acac})_{3}\left(\mathrm{H}_{2} \mathrm{O}\right)_{2}$ into MWCNTs did not enhance the SMM properties, this work shows that it is possible to control the coordination environment and tune the magnetic properties of SMMs via encapsulation. In addition, we believe that the magnetic and electronic properties of lanthanoid SMM-CNT hybrids can be combined to bring about new applications in devices, like spintronic devices.

Supplementary Materials: The following are available online at www.mdpi.com/1996-1944/10/1/7/s1. Figure S1: TEM image and EDX spectrum of empty MWCNT, Figure S2: $\chi_{\mathrm{CNT}}$ and $\chi_{\mathrm{CNT}} T$ vs. $T$ plots for MWCNT and Dy $(\mathrm{acac})_{3}\left(\mathrm{H}_{2} \mathrm{O}\right)_{2} @$ MWCNTs without correction for the diamagnetism of the MWCNTs, Figure S3: Temperature-dependence of the in-phase $\left(\chi^{\prime}\right)$ and out-of-phase $\left(\chi^{\prime \prime}\right)$ AC magnetic susceptibilities of MWCNT and Dy $(\mathrm{acac})_{3}\left(\mathrm{H}_{2} \mathrm{O}\right)_{2} @ M W C N T s$, Figure S4: Frequency-dependence of $\chi^{\prime}$ and $\chi^{\prime \prime} \mathrm{AC}$ magnetic susceptibilities of Dy $(\text { acac })_{3}\left(\mathrm{H}_{2} \mathrm{O}\right)_{2}$, Table S1: Selected values of $\Delta E$ and $\tau_{0}$ for Dy $(\mathrm{acac})_{3}\left(\mathrm{H}_{2} \mathrm{O}\right)_{2} @ M W C N T s$.

Acknowledgments: This work was supported by CREST, JST, a Grant-in-Aid for Scientific Research (S) (grant No. 20225003, Masahiro Yamashita), Grant-in-Aid for Scientific Research (C) (grant No. 15K05467, Keiichi Katoh), Grant-in-Aid for Young Scientists (B) (grant No. 24750119, Keiichi Katoh) from the Ministry of Education, Culture, Sports, Science, and Technology, Japan (MEXT). Ryo Nakanishi thanks Shorai Foundation for Science and Technology. We thank Takamichi Miyazaki (Technical Division, Department of Engineering, Tohoku University) for the support in the TEM and EDX analyses.

Author Contributions: Ryo Nakanishi, Keiichi Katoh and Masahiro Yamashita conceived and designed the experiments; Mudasir Ahmad Yatoo performed the experiments; Ryo Nakanishi, Mudasir Ahmad Yatoo and Keiichi Katoh analyzed the data; Ryo Nakanishi, Brian K. Breedlove and Masahiro Yamashita wrote the paper.

Conflicts of Interest: The authors declare no conflict of interest. The funding sponsors had no role in the design of the study; in the collection, analyses, and interpretation of data, in the writing of the manuscript, and in the decision to publish the results. 


\section{References}

1. Sessoli, R.; Gatteschi, D.; Caneschi, A.; Novak, M.A. Magnetic bistability in a metal-ion cluster. Nature 1993, 365, 141-143. [CrossRef]

2. Ishikawa, N.; Sugita, M.; Ishikawa, T.; Koshihara, S.-Y.; Kaizu, Y. Lanthanide double-decker complexes functioning as magnets at the single-molecular level. J. Am. Chem. Soc. 2003, 125, 8694-8695. [CrossRef] [PubMed]

3. Woodruff, D.N.; Winpenny, R.E.P.; Layfield, R.A. Lanthanide single-molecule magnets. Chem. Rev. 2013, 113, 5110-5148. [CrossRef] [PubMed]

4. Horii, Y.; Katoh, K.; Yasuda, N.; Breedlove, B.K.; Yamashita, M. Effects of f-f interactions on the single-molecule magnet properties of terbium(III)-phthalocyaninato quintuple-decker complexes. Inorg. Chem. 2015, 54, 3297-3305. [CrossRef] [PubMed]

5. Thomas, L.; Lionti, F.; Ballou, R.; Gatteschi, D.; Sessoli, R.; Barbara, B. Macroscopic quantum tunnelling of magnetization in a single crystal of nanomagnets. Nature 1996, 383, 145-147. [CrossRef]

6. Friedman, J.R.; Sarachik, M.P.; Tejada, J.; Ziolo, R. Macroscopic measurement of resonant magnetization tunneling in high-spin molecules. Phys. Rev. Lett. 1996, 76, 3830-3833. [CrossRef] [PubMed]

7. Gatteschi, D.; Sessoli, R. Quantum tunneling of magnetization and related phenomena in molecular materials. Angew. Chem. Int. Ed. 2003, 42, 268-297. [CrossRef] [PubMed]

8. Mannini, M.; Pineider, F.; Danieli, C.; Totti, F.; Sorace, L.; Sainctavit, P.; Arrio, M.A.; Otero, E.; Joly, L.; Cezar, J.C.; et al. Quantum tunnelling of the magnetization in a monolayer of oriented single-molecule magnets. Nature 2010, 468, 417-421. [CrossRef] [PubMed]

9. Ardavan, A.; Rival, O.; Morton, J.J.L.; Blundell, S.J.; Tyryshkin, A.M.; Timco, G.A.; Winpenny, R.E.P. Will spin-relaxation times in molecular magnets permit quantum information processing? Phys. Rev. Lett. 2007, 98, 057201. [CrossRef] [PubMed]

10. Mannini, M.; Pineider, F.; Sainctavit, P.; Danieli, C.; Otero, E.; Sciancalepore, C.; Talarico, A.M.; Arrio, M.-A.; Cornia, A.; Gatteschi, D.; et al. Magnetic memory of a single-molecule quantum magnet wired to a gold surface. Nat. Mater. 2009, 8, 194-197. [CrossRef] [PubMed]

11. Komeda, T.; Isshiki, H.; Liu, J.; Zhang, Y.-F.; Lorente, N.; Katoh, K.; Breedlove, B.K.; Yamashita, M. Observation and electric current control of a local spin in a single-molecule magnet. Nat. Commun. 2011, 2, 217. [CrossRef] [PubMed]

12. Bogani, L.; Wernsdorfer, W. Molecular spintronics using single-molecule magnets. Nat. Mater. 2008, 7, 179-186. [CrossRef] [PubMed]

13. Leuenberger, M.N.; Loss, D. Quantum computing in molecular magnets. Nature 2001, 410, $789-793$. [CrossRef] [PubMed]

14. Urdampilleta, M.; Klyatskaya, S.; Cleuziou, J.P.; Ruben, M.; Wernsdorfer, W. Supramolecular spin valves. Nat. Mater. 2011, 10, 502-506. [CrossRef] [PubMed]

15. Candini, A.; Klyatskaya, S.; Ruben, M.; Wernsdorfer, W.; Affronte, M. Graphene spintronic devices with molecular nanomagnets. Nano Lett. 2011, 11, 2634-2639. [CrossRef] [PubMed]

16. Del Carmen Giménez-López, M.; Moro, F.; La Torre, A.; Gómez-García, C.J.; Brown, P.D.; van Slageren, J.; Khlobystov, A.N. Encapsulation of single-molecule magnets in carbon nanotubes. Nat. Commun. 2011, 2, 407. [CrossRef] [PubMed]

17. Aulakh, D.; Pyser, J.B.; Zhang, X.; Yakovenko, A.A.; Dunbar, K.R.; Wriedt, M. Metal-organic frameworks as platforms for the controlled nanostructuring of single-molecule magnets. J. Am. Chem. Soc. 2015, 137, 9254-9257. [CrossRef] [PubMed]

18. Jiang, S.-D.; Wang, B.-W.; Su, G.; Wang, Z.-M.; Gao, S. A Mononuclear dysprosium complex featuring single-molecule-magnet behavior. Angew. Chem. Int. Ed. 2010, 49, 7448-7451. [CrossRef] [PubMed]

19. Ajayan, P.M.; Iijima, S. Capillarity-induced filling of carbon nanotubes. Nature 1993, 361, 333-334. [CrossRef]

20. Yudasaka, M.; Ajima, K.; Suenaga, K.; Ichihashi, T.; Hashimoto, A.; Iijima, S. Nano-extraction and nano-condensation for $\mathrm{C}_{60}$ incorporation into single-wall carbon nanotubes in liquid phases. Chem. Phys. Lett. 2003, 380, 42-46. [CrossRef]

21. Yu, A.; Bekyarova, E.; Itkis, M.E.; Fakhrutdinov, D.; Webster, R.; Haddon, R.C. Application of centrifugation to the large-scale purification of electric arc-produced single-walled carbon nanotubes. J. Am. Chem. Soc. 2006, 128, 9902-9908. [CrossRef] [PubMed] 
22. Bi, Y.; Guo, Y.N.; Zhao, L.; Guo, Y.; Lin, S.Y.; Jiang, S.D.; Tang, J.; Wang, B.W.; Gao, S. Capping ligand perturbed slow magnetic relaxation in dysprosium single-ion magnets. Chem. Eur. J. 2011, 17, 12476-12481. [CrossRef] [PubMed]

23. Katoh, K.; Breedlove, B.K.; Yamashita, M. Symmetry of octa-coordination environment has a substantial influence on dinuclear $\mathrm{Tb}^{\mathrm{III}}$ triple-decker single-molecule magnets. Chem. Sci. 2016, 7, 4329-4340. [CrossRef]

24. Luis, F.; Bartolomé, J.; Fernández, J.F.; Tejada, J.; Hernández, J.M.; Zhang, X.X.; Ziolo, R. Thermally activated and field-tuned tunneling in $\mathrm{Mn}_{12}$ Ac studied by ac magnetic susceptibility. Phys. Rev. B 1997, 55, 11448-11456. [CrossRef]

25. Bartolomé, J.; Filoti, G.; Kuncser, V.; Schinteie, G.; Mereacre, V.; Anson, C.E.; Powell, A.K.; Prodius, D.; Turta, C. Magnetostructural correlations in the tetranuclear series of $\left\{\mathrm{Fe}_{3} \mathrm{LnO}_{2}\right\}$ butterfly core clusters: Magnetic and Mössbauer spectroscopic study. Phys. Rev. B 2009, 80, 014430. [CrossRef]

26. Ferrando-Soria, J.; Cangussu, D.; Eslava, M.; Journaux, Y.; Lescouëzec, R.; Julve, M.; Lloret, F.; Pasán, J.; Ruiz-Pérez, C.; Lhotel, E.; et al. Rational enantioselective design of chiral heterobimetallic single-chain magnets: Synthesis, crystal structures and magnetic properties of oxamato-bridged $\mathrm{M}^{\mathrm{II}} \mathrm{Cu}^{\mathrm{II}}$ chains (M=Mn, Co). Chem. Eur. J. 2011, 17, 12482-12494. [CrossRef] [PubMed]

27. Gass, I.A.; Moubaraki, B.; Langley, S.K.; Batten, S.R.; Murray, K.S. A $\pi-\pi$ 3D network of tetranuclear $\mu 2 / \mu 3$-carbonato Dy(III) bis-pyrazolylpyridine clusters showing single molecule magnetism features. Chem. Commun. 2012, 48, 2089-2091. [CrossRef] [PubMed]

(C) 2016 by the authors; licensee MDPI, Basel, Switzerland. This article is an open access article distributed under the terms and conditions of the Creative Commons Attribution (CC-BY) license (http://creativecommons.org/licenses/by/4.0/). 